\title{
An Acid-Base Electrochemical Flow Battery as energy storage system
}

\author{
Alfonso Sáez, Vicente Montiel ${ }^{*}$, Antonio Aldaz ${ }^{\dagger}$ \\ Institute of Electrochemistry, University of Alicante, 03080 Alicante, Spain.
}

\section{Abstract}

In this paper, we present a new Acid-Base Electrochemical Flow Battery (ABEFB). This system is composed of acidic and alkaline solutions, both with a high supporting electrolyte concentration. These solutions are separated by a proton exchange membrane, using hydrogen as both a reactant and a product. Under this configuration, neutralization energy is used as electromotive force. Thus, in the charging process, hydrogen is oxidized to form hydronium ions (hydrogen oxidation reaction -HOR-) (positive electrode) that acidifies positive electrolyte or posilyte, while hydrogen is formed from water (hydrogen evolution reaction -HER-) (negative electrode) that basifies negative electrolyte or negalyte. On the other hand, during the discharging process, both electrolytes are neutralized through hydrogen oxidation and hydrogen evolution reactions. A platinised titanium electrode is chosen for HER and a platinum-catalysed gas diffusion electrode is used for HOR. This proof of concept has been verified for several charge capacities obtaining a maximum power density of $20 \mathrm{~mW} \mathrm{~cm}^{-2}$ at $49 \mathrm{~mA} \mathrm{~cm}{ }^{-2}$. In this sense, faradaic efficiency close to $95 \%$ and energy efficiency of $55 \%$ are also obtained. Finally, the reuse of produced hydrogen is an interesting aspect to be considered.

Keywords: hydrogen, acid, base, energy storage system, redox flow battery.

\footnotetext{
* Corresponding Author: e-mail: vicente.montiel@ua.es phone: 00349659098 14, fax: 0034965909814

${ }^{\dagger}$ Died on 27th October 2015.
} 


\section{Introduction}

In Hydrogen-based Energy Storage Systems (HESS) [1, 2] hydrogen is considered to be an alternative energetic vector, either as fuel or as a transmission element. On the one hand, hydrogen-based fuel cells, which have

5 been widely studied by the scientific community, have become a commercial reality, as reflected by the industrial development in this field [3, 4]. It is also important to highlight that Hydrogen-based Uninterruptible Power Supply (HUPS) systems [5], are mainly composed of: 1) an electrolyser connected to a renewable power source (considering or not battery storage systems), 2) a Proton Exchange Membrane Fuel Cell (PEMFC) and 3) a central control, and used to distribute energy, produced at the PEMFC, to the final consumption point or to a battery storage. In this case, the electrolyser is used to produce hydrogen from water, which is then stored, normally in metal hydride tanks, and later used in the PEMFC as fuel while air or oxygen are used in the cathode [6]. Therefore, energy can be stockpiled as hydrogen or in a battery. In this communication, we propose the use of a HUPS using hydrogen both as reactant and product. In this case, energy is stored or generated depending on whether the system is used as a galvanic or as an electrolytic cell, respectively.

As it is well-known, the $\mathrm{H}^{+} / \mathrm{H}_{2}$ redox potential is dependent on $\mathrm{pH}$ and its value decreases in $\left(1.98 \cdot 10^{-4} \cdot \mathrm{T}\right) \mathrm{V}$ per $\mathrm{pH}$ unit, $\mathrm{T}$ being the temperature in $\mathrm{K}$. Thus, two solutions with different $\mathrm{pH}$ values show different electrode potentials [7]. Based on this fact, we propose an energy storage system in which two solutions are separated by a proton exchange membrane. One of these solutions should be acidified and the other should be basified, using hydrogen as both a reactant and a product. Thus, if a high supporting electrolyte concentration is used in both solutions, the neutralization energy obtained from these solutions may be used as electromotive force in this energy storage battery.

All these facts lead us to define a new Acid-Base Electrochemical Flow Battery (ABEFB) as a pseudo-redox flow battery [8, 9]. In this kind of charge-discharge energy storage systems, electrolytes are called positive electrolyte or posilyte and negative electrolyte or negalyte (solutions in contact with positive and negative electrodes, respectively), instead of anolyte and catholyte. 
Figure 1 illustrates the processes taking place. During the charging process, a potential difference, mainly obtained from renewable energy sources, is applied between both electrodes and water is reduced to hydrogen at the negative electrode:

$5 \quad 2 \mathrm{H}_{2} \mathrm{O}+2 \mathrm{e} \rightarrow \mathrm{H}_{2}+2 \mathrm{OH}^{-}$

Whereas hydronium ions are formed from hydrogen oxidation at the positive electrode:

$\mathrm{H}_{2}+2 \mathrm{H}_{2} \mathrm{O} \rightarrow 2 \mathrm{H}_{3} \mathrm{O}^{+}+2 \mathrm{e}$

Thus, the overall reaction is: $2 \mathrm{H}_{2} \mathrm{O} \rightarrow \mathrm{H}_{3} \mathrm{O}^{+}+\mathrm{OH}^{-}$. As reflected in the former reactions, both posilyte and negalyte solutions suffer an increase in acidity and alkalinity because of the ionic transport through the membrane, which is carried out by the supporting electrolyte. Thus, charge capacity is associated with final obtained values of hydronium or hydroxide activity. Interestingly enough, hydrogen is both produced and consumed so, during the charging process there is hydrogen self-supply.

On the other hand, energy can be obtained from the system during the discharging process. In alkaline medium hydrogen oxidation to water takes place at the negative electrode:

$\mathrm{H}_{2}+2 \mathrm{OH}^{-} \rightarrow 2 \mathrm{H}_{2} \mathrm{O}+2 \mathrm{e}$

while at the positive electrode hydronium ions are reduced to hydrogen:

$2 \mathrm{H}_{3} \mathrm{O}^{+}+2 \mathrm{e} \rightarrow \mathrm{H}_{2}+2 \mathrm{H}_{2} \mathrm{O}$

Thus, during the discharging process, the overall reaction is also: $\mathrm{H}_{3} \mathrm{O}^{+}+\mathrm{OH}^{-}$ $\rightarrow 2 \mathrm{H}_{2} \mathrm{O}$, so both solutions are neutralized. Moreover, as in the charging process, there is hydrogen self-supply and ionic transport through the membrane is kept by the supporting electrolyte.

The aim of this communication is to verify this new concept of Acid-Base Electrochemical Flow Battery (ABEFB) or "all-hydrogen flow battery". In this sense, we have separately studied both charging and discharging processes for several charge capacities. Both charging and discharging processes have been 
evaluated using charging or discharging and power curves as well as constant current density experiments.

\section{Material and methods}

5 A filter-press electrochemical reactor with a geometric electrode area of $4 \mathrm{~cm}^{2}$ has been used. A platinised titanium electrode $(2.3 \mu \mathrm{m}$ average thickness manufactured by ID Electroquimica, S.L.) has been chosen for hydrogen evolution reaction. Moreover, a homemade platinum-catalysed gas diffusion electrode with a catalytic loading of $1 \mathrm{mg} \mathrm{cm}^{-2}$ has been used for hydrogen oxidation reaction. The utilized electrocatalyst was a $20 \%$ wt. Pt on Vulcan XC72R (HisPEC 3000 Fuel Cell Catalyst, Johnson Matthey) and electrocatalyst / Nafion ratio in catalytic layer of 60/40. In addition, microporous layer (MPL) in gas diffusion electrode with $2 \mathrm{mg}$ Vulcan $X C-72 \mathrm{R} \mathrm{cm}^{-2}$ and a PTFE/Vulcan XC$72 \mathrm{R}$ ratio of $60 / 40$ was produced. Otherwise, the cationic exchange membrane used was a Nafion 112 and an equal volume of negalyte and posilyte (50 mL) was used in all experiments. Note that, this is a proof of concept so platinum based electrodes and Nafion 112, as cationic exchange membrane, are nonoptimized options, mainly economically. A future optimization should include the use of non-noble metals as electrocatalysts and cheaper cation exchange membranes.

Posilyte and negalyte starting solutions had the same concentrations of $\mathrm{HCl}$ and $\mathrm{NaOH}$ and different experiments with several initial concentrations were carried out. In this way, four theoretical charge capacities were defined for the ABEFB. Moreover, a $2 \mathrm{M} \mathrm{NaCl}$ concentration was used as supporting electrolyte in both solutions. In all experiments, a peristaltic pump (Ismatel Reglo DIG MS/CA 2$8 C$ ) provided both posilyte and negalyte at $50 \mathrm{~mL} \mathrm{~min}^{-1}$ flow from their vessels with an Ar atmosphere and gas diffusion electrode was fed by hydrogen (Praxair, purity 99.999\%) at $50 \mathrm{ml} \mathrm{min}^{-1}$. It is important to note that, posilyte is fed to gas diffusion compartment (HOR) in charge process and to platinized titanium compartment (HER) in discharge process. Concurrently, negalyte is also fed to gas diffusion compartment (HOR) in discharge process and to platinized titanium compartment (HER) in charge process. Thus, solutions are 
interchanged in charge and discharge process or vice versa. In this sense, diagram of this system is shown where each part of completed system (figure 2.a.) and electrochemical reactor (figure 2.b.) is described in detail.

Current and power were normalized to the geometric area of the electrode and plotted as current and power densities. Experiments were carried out using a Metrohm Autolab PGSTAT30 Potentiostat/Galvanostat. Moreover, electrode potentials versus $\mathrm{Ag} / \mathrm{AgCl}$ reference were checked using a FLUKE 179 multimeter. These reference electrodes are connected with the solutions of the compartments through a Teflon capillary tube as is described in figure 2.c. Finally, temperature effect was analysed both in the charging and discharging processes. Thus, thermotastted vessels at tested temperatures of $293,303,313$ and $323 \mathrm{~K}$ have been used.

\section{Results and Discussion}

As mentioned above, four experiments with four different theoretical charge capacities were carried out at $293 \mathrm{~K}$. In order to obtain said theoretical charge capacities, $0.10,0.25,0.50$ and $1 \mathrm{M}$ starting solutions of both $\mathrm{NaOH}$ and $\mathrm{HCl}$ with $2 \mathrm{M} \mathrm{NaCl}$ as supporting electrolyte were prepared $(\mathrm{pH}$ values of 12.0, 12.1, 12.3 and 12.5 for $\mathrm{NaOH}$ starting solutions and $0.7,0.5,0.3$ and 0.2 for $\mathrm{HCl}$ starting solutions, respectively). For these solutions, theoretical charge capacities of 134, 335, 670 and $1340 \mathrm{~mA}$ h were defined. Figure 3a shows the discharging, charging and power curves for these experiments. Firstly, open circuit voltage (OCV) values of $0.704,0.741,0.785$ and $0.814 \mathrm{~V}$ for 134,335 , 670 and $1340 \mathrm{~mA} \mathrm{~h}$ charge capacities were obtained. As shown, higher OCV values were obtained with increased charge capacities (higher $\mathrm{pH}$ difference). Nevertheless, the charge curves show very similar profiles for the different tested charge capacities. Moreover, while during charging charge curve profile is not related to charge capacities, during discharging curves are dependent on theoretical charge capacities and the higher the tested charge capacity, the higher the current densities obtained. This increase, as shown, is lower in the two higher theoretical charge capacities. This behaviour could be attributed to mass transport problems at both electrodes due to low concentrations of 
hydronium and hydroxide ions in the posilyte and negalyte, respectively. Furthermore, discharging curves are associated with power plots for each one of the tested charge capacities. Maximum power density also increases at higher theoretical charge capacities (aforementioned trend). In this case, a maximum power density value of $20 \mathrm{~mW} \mathrm{~cm}^{-2}$ for a current density of $49 \mathrm{~mA}$ $\mathrm{cm}^{-2}$ was obtained, similar to the obtained values in other electric storage systems [10]. Moreover, it is important to highlight that, in charging processes, no significant differences in total overpotential values were observed for the tested charge capacities.

In addition, four charging/ discharging cycles for charge capacities of 1340 and $134 \mathrm{~mA}$ h (highest and lowest values) (fig. 3b) have been carried out in order to verify reproducibility in this proof of concept. Regarding this choice, charge capacities were associated to starting solutions and these were tested to consider several batteries with different charge capacities or different states of charge at the same battery. In this sense, current densities and duration of experiments were chosen considering a variation below 5\% for each theoretical charge capacity. Despite this fact, the faradaic efficiency (ratio of charge released during the discharge to the charge required to charge the battery) was determined by standard acid-base titration of posilyte and negalyte. In this sense, faradaic efficiencies close to $95 \%$ were determined because around 5\% of hydronium ion diffusion through the cationic membrane has been detected. Finally, a maximum energy efficiency (ratio of the output of electrical energy during discharge of the cell to the input of electrical energy during the charging cycle) of $55 \%$ was obtained at a constant current density and constant charge.

25 These values were obtained considering $1340 \mathrm{~mA}$ h system. Regarding $134 \mathrm{~mA}$ $\mathrm{h}$, note that, irregular trend in cell potential values in discharge cycles is observed thus this charge capacity should be considered as lower limit value (lower hydronium and hydroxyl ion concentration) in further optimization studies.

To obtain more information about the behaviour of each electrode, $\mathrm{Ag} / \mathrm{AgCl}$ reference electrodes were positioned very close to the negative and positive electrodes. Therefore, three different electric potential differences were measured versus current density: 1) negative electrode potential, 2) positive electrode potential and 3) potential difference between the reference electrodes, 
mainly with membrane ohmic drop included. All the aforementioned values were plotted versus current densities for $1340 \mathrm{~mA}$ h charge capacity experiment at $293 \mathrm{~K}$ in both charging (fig 4a) and discharging processes (fig 4b). Furthermore, the reactions involved are shown in these figures. Regarding these potential values, a total concordance was observed between overall potential difference and the corresponding individual potentials. Moreover, the electric potential difference between the reference electrodes and current density is similar for both charging and discharging processes. A maximum value of $100 \mathrm{mV}$ at 70 $\mathrm{mA} \mathrm{cm}^{-2}$ is shown, so the membrane ohmic drop process may only be assumed, according membrane and solutions resistance. Nonetheless, a detailed analysis of these electrode potentials reveals that overpotentials from hydrogen evolution reaction (HER) and hydrogen oxidation reaction (HOR) in alkaline medium are higher than the same reactions in acidic medium. Besides, HOR in alkaline medium (discharging process) shows the highest overpotential values. Therefore, the main problem is to improve the HOR efficiency in an alkaline medium. In this sense, hydroxyl ions access to the catalytic site in the three phase system (gas: hydrogen, solid: catalyst, liquid: electrolyte) might be evaluated and optimized. Unfortunately, from analysis of current literature on hydrogen electrooxidation in an alkaline medium, only fuel cell references have been found and it can be concluded that further research is required concerning the understanding of this process in fuel cells with alkaline electrolytes [11-14].

Finally, the effect of the temperature for the $1340 \mathrm{~mA}$ h theoretical charge capacity experiment has been evaluated using four different temperature values $(293,303,313$ and $323 \mathrm{~K})$. In this sense, charging, discharging and power curves were obtained using thermostated solutions (fig. 5). According to these experiments, maximum power density improved with an increase in temperature: from $20 \mathrm{~mW} \mathrm{~cm}^{-2}$ at $293 \mathrm{~K}$ to $24 \mathrm{~mW} \mathrm{~cm}^{-2}$ at $323 \mathrm{~K}$.

\section{Conclusions}

In this paper, the concept of a new Acid-Base Electrochemical Flow Battery (ABEFB), using hydrogen both as a reactant and a product, is validated. The system is composed of two solutions, one is an acidic and the other an alkaline solution; a high supporting electrolyte concentration was used, in both solutions, 
separated by a proton exchange membrane. Therefore, neutralization energy from these solutions may be used as electromotive force in this energy storage battery.

Charging and discharging processes were studied separately for several

5 defined charge capacities. Negalyte and posilyte solutions with the same concentration of both $\mathrm{NaOH}$ and $\mathrm{HCl}$ were prepared and several experiments with different theoretical charge capacities (134, 335, 670 and $1340 \mathrm{~mA} \mathrm{~h})$ were carried out. Discharging, charging and power curves were plotted to analyse the electrochemical behaviour of the system. During discharging, the higher the theoretical charge capacity, the higher were the current and power density values obtained. Furthermore, the following maximum values were obtained: a power density of $20 \mathrm{~mW} \mathrm{~cm}^{-2}$ at $49 \mathrm{~mA} \mathrm{~cm}^{-2}$, energy efficiency of $55 \%$ and a faradaic efficiency close to $95 \%$. However, in an alkaline medium a higher overpotential was observed, especially in the HOR at the discharging process. Thus, this study would profit from further research on HOR in alkaline medium.

\section{Funding}

This research did not receive any specific grant from funding agencies in the public, commercial, or not-for-profit sectors. 


\section{References}

[1] Y. Yürüm, A. Taralp, T.N. Veziroglu, Storage of hydrogen in nanostructured carbon materials, Int J Hydrogen Energ, 2009; 34: 3784-3798.

5 [2] G. Marbán, T. Valdés-Solís, Towards the hydrogen economy?, Int J Hydrogen Energ, 2007; 32: 1625-1637.

[3] R. Borup, J. Meyers, B. Pivovar, Y.S. Kim, R. Mukundan, N. Garland, D. Myers, M. Wilson, F. Garzon, D. Wood, P. Zelenay, K. More, K. Stroh, T. Zawodzinski, J. Boncella, J.E. McGrath, M. Inaba, K. Miyatake, M. Hori, K. Ota, Z. Ogumi, S. Miyata, A. Nishikata, Z. Siroma, Y. Uchimoto, K. Yasuda, K.I. Kimijima, N. Iwashita, Scientific aspects of polymer electrolyte fuel cell durability and degradation, Chem Rev, 2007; 107: 3904-3951.

15 [4] V. Mehta, J.S. Cooper, Review and analysis of PEM fuel cell design and manufacturing, J Power Sources, 2003; 114: 32-53.

[5] E. Varkaraki, N. Lymberopoulos, E. Zoulias, D. Guichardot, G. Poli, Hydrogen-based uninterruptible power supply, Int J Hydrogen Energ, 2007; 32: 1589-1596.

[6] M. Carmo, D.L. Fritz, J. Mergel, D. Stolten, A comprehensive review on PEM water electrolysis, Int J Hydrogen Energ, 2013; 38: 4901-4934.

[7] W. Nernst, Die elektromotorische Wirksamkeit der Jonen, Z Phys Chem, 1889; 4: 129-181.

[8] B. Dunn, H. Kamath, J.M. Tarascon, Electrical energy storage for the grid: A battery of choices, Science, 2011; 334: 928-935.

[9] A.Z. Weber, M.M. Mench, J.P. Meyers, P.N. Ross, J.T. Gostick, Q. Liu, Redox flow batteries: A review, J Appl Electrochem, 2011; 41: 1137-1164.

[10] H. Ibrahim, A. Ilinca, J. Perron, Energy storage systems-Characteristics and comparisons, Renew Sust Energ Rev, 2008; 12: 1221-1250.

[11] D.E. Ramaker, C. Roth, Nature of the Intermediate Binding Sites in Hydrogen Oxidation/Evolution over $\mathrm{Pt}$ in Alkaline and Acidic Media, ChemElectroChem, 2015; 2: 1582-1594.

[12] F. Alcaide, E. Brillas, P.L. Cabot, Hydrogen oxidation reaction in a Ptcatalyzed gas diffusion electrode in alkaline medium, J Electro Soc, 2005; 152: E319-E327.

[13] J.A. Vega, S. Smith, W.E. Mustain, Hydrogen and methanol oxidation reaction in hydroxide and carbonate alkaline media, J Electro Soc, 2011; 158: B349-B354.

[14] M.R. Tarasevich, O.V. Korchagin, Electrocatalysis and $\mathrm{pH}$ (a review), Russ J Electrochem, 2013; 49: 600-618. 


\section{Figure Captions}

Fig. 1. Scheme of a) charging and b) discharging processes from Acid-Base 5 Electrochemical Flow Battery (ABEFB).

Fig. 2. Diagram of a) completed system: (i) hydrogen compartment, (ii) $\mathrm{H}_{2}-\mathrm{GDE}$, (iii) nafion 112, (iv) Ti/Pt electrode, (v) posilyte solution -black line represents flux in charge process and dashed blue line represents flux in discharge process -, (vi) negalyte solution -idem aforementioned comments in posilyte solution-, (vii) thermostatted vessels; b) electrochemical reactor: (1) clamping plates and flux distributors, (2) $100 \mu \mathrm{m}$ - gasket, (3) $3 \mathrm{~mm}$ butyl rubber gasket as compartment, (4) current collector, (5) $\mathrm{H}_{2}$-gas diffusion electrode, (6) nafion 112, (7) Ti/Pt electrode, (8) placement of reference electrodes, (9) clamping screw; c) description of reference electrode placement in the $3 \mathrm{~mm}$ butyl rubber compartment : (10) $1.5 \mathrm{~mm}$ Teflon capillary tube, (11) $10 \mathrm{~mL}$ plastic syringe, (12) gasket ring, (13) $\mathrm{Ag} / \mathrm{AgCl}$ reference electrode.

Fig. 3. Electrochemical behaviour: a) discharging and charging curves (filled symbol, left axis) and power curves (empty symbol + solid line, right axis) b) charging/ discharging cycles for charge capacities of 134 (black) and 1340 (blue) $\mathrm{mA} \mathrm{h}$.

Fig. 4. Electrode potential and values of potential difference in the Acid-Base Electrochemical Flow Battery for a) charging and b) discharging processes. Charge capacity: $1340 \mathrm{~mA} \mathrm{~h}$.

Fig. 5. Polarization and charge curves (filled symbol, left axis) and power curves (empty symbol + solid line, right axis) for several temperatures. Charge capacity: $1340 \mathrm{~mA}$ h. 


\section{CHARGE}

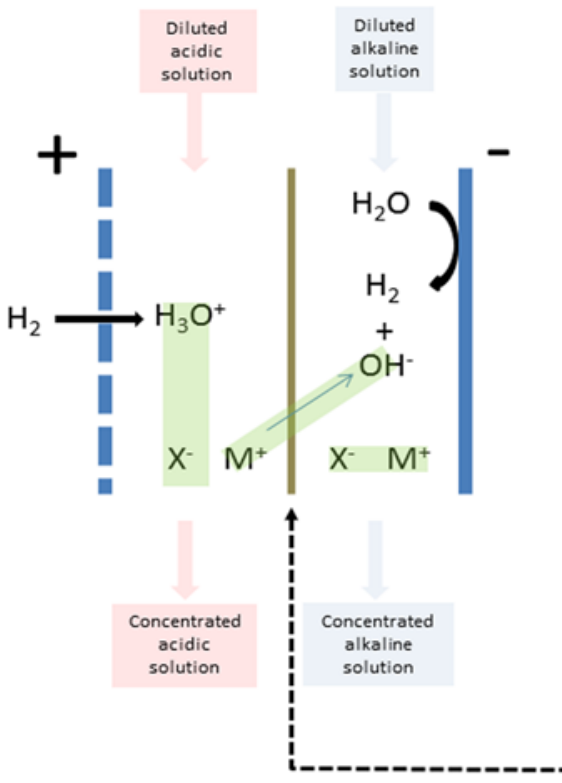

DISCHARGE

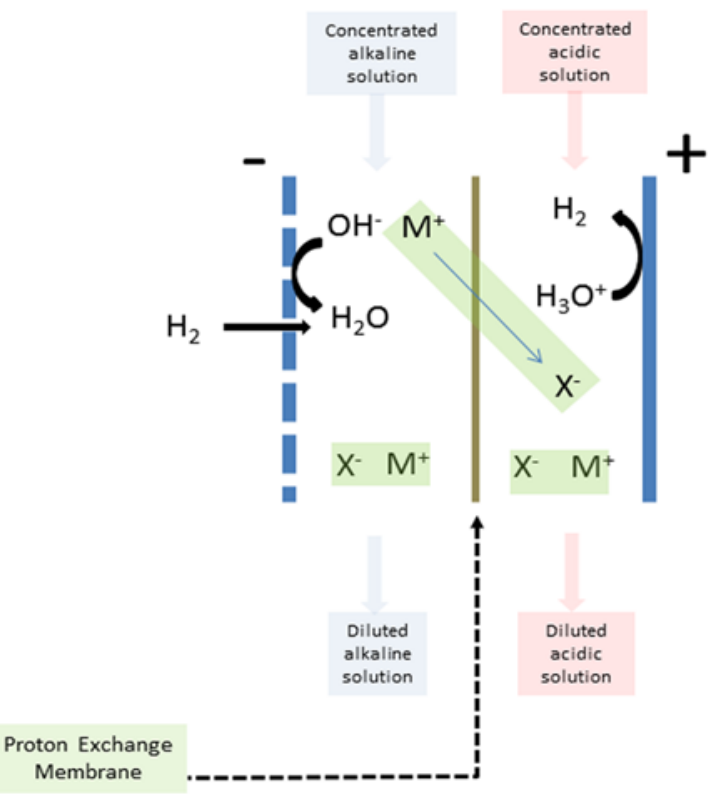

Figure 1 
a)

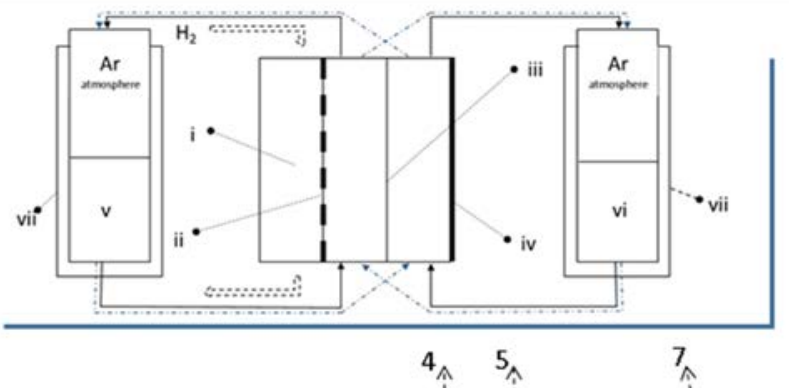

c)

b)
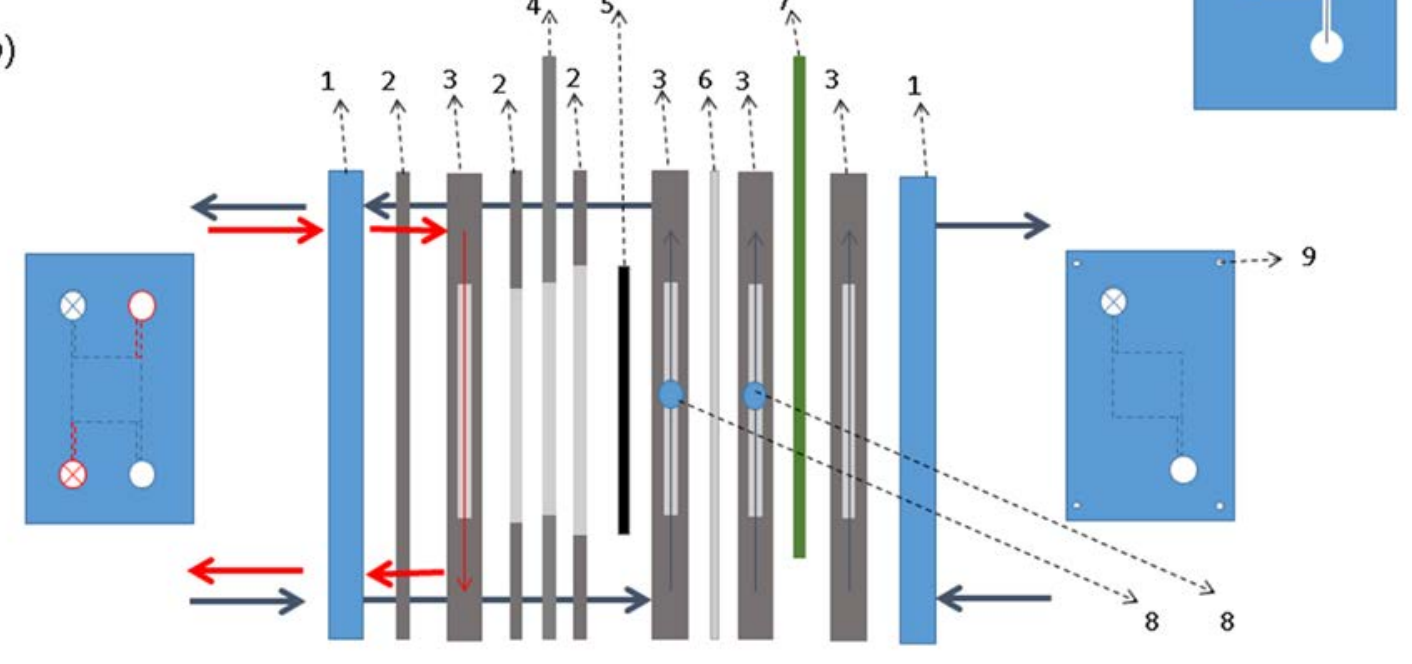

solutions

$\mathrm{H}_{2}$

Figure 2 
a)

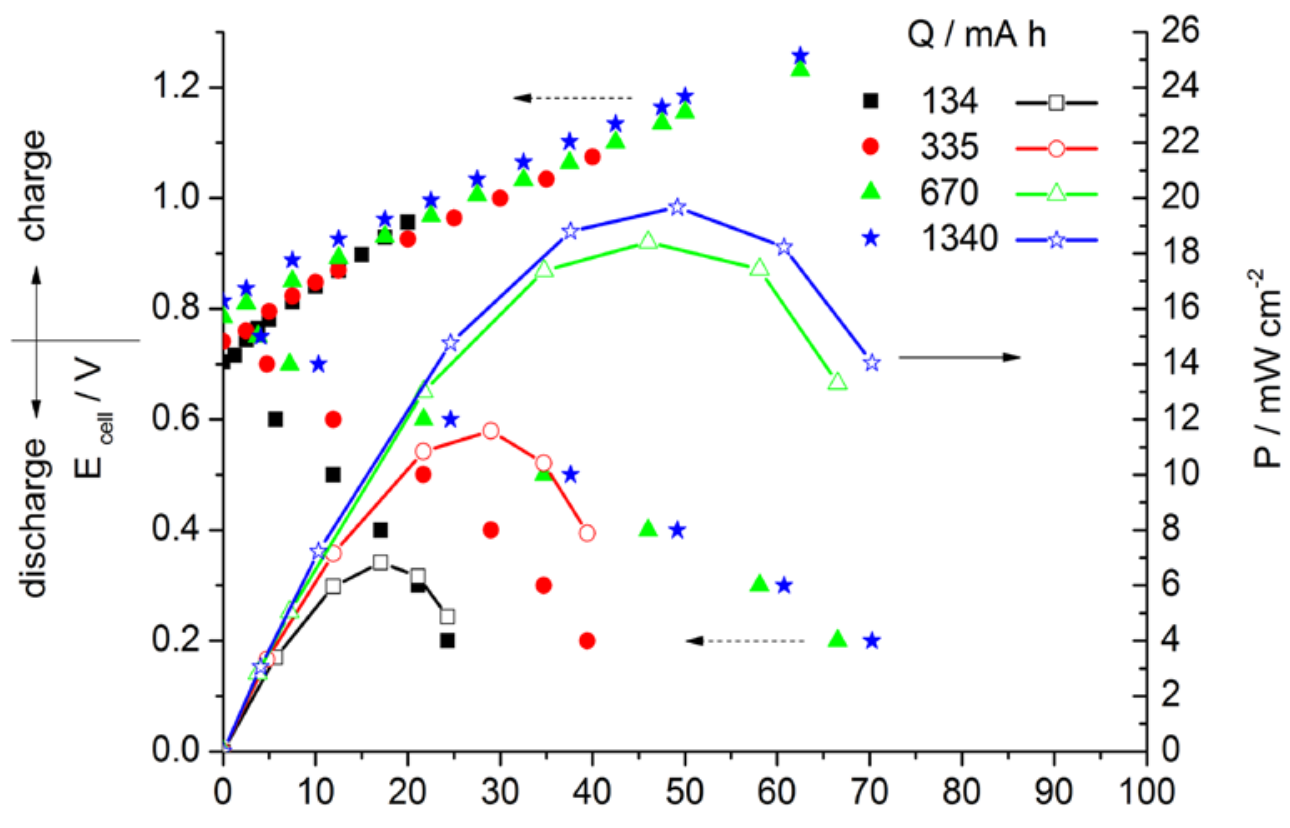

b)

$\mathrm{j} / \mathrm{mA} \mathrm{cm}^{-2}$

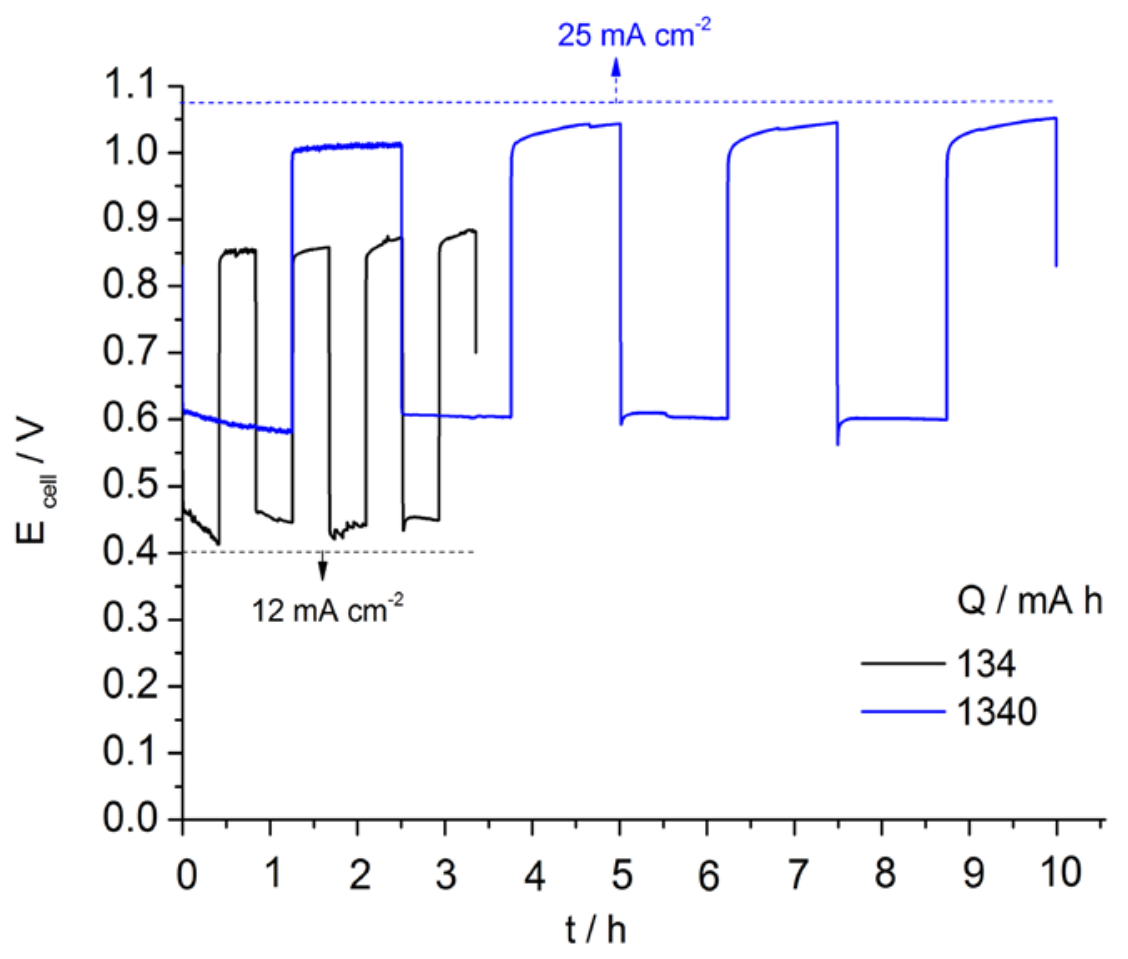

Figure 3 
a) Charging process

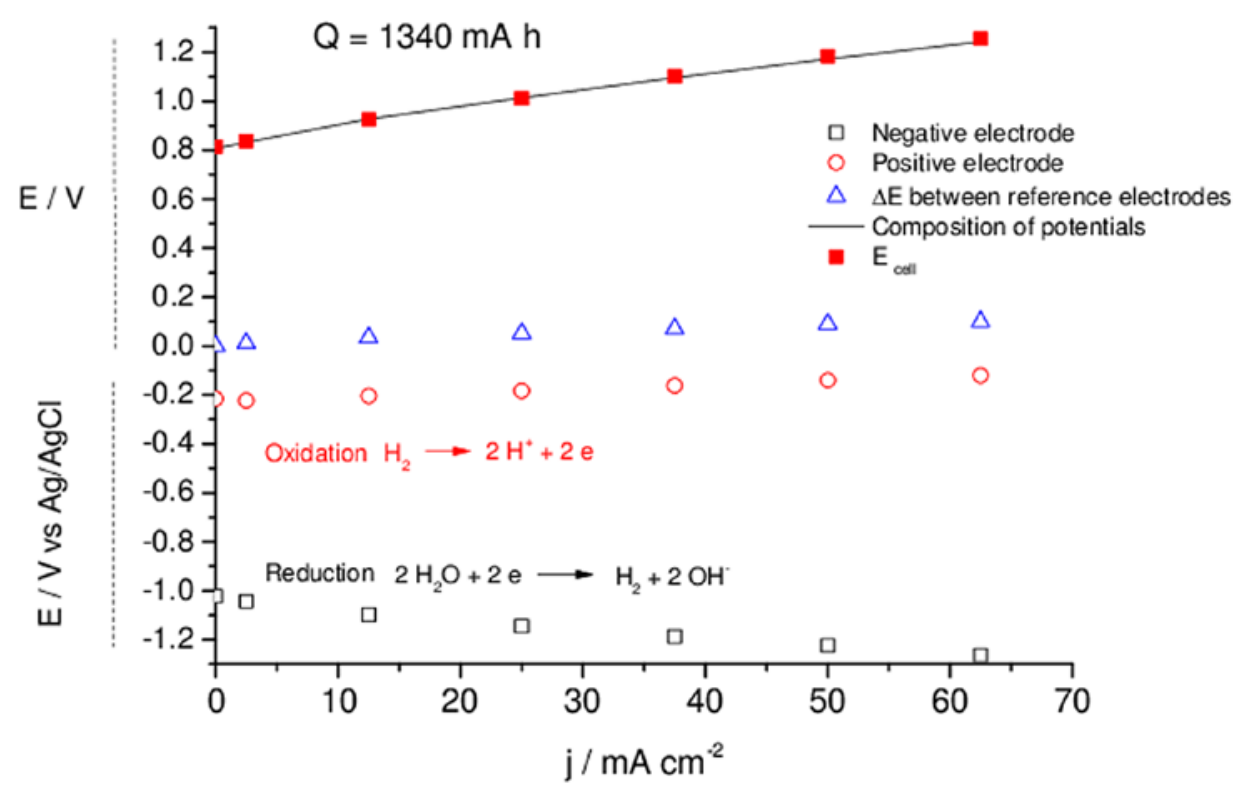

b)

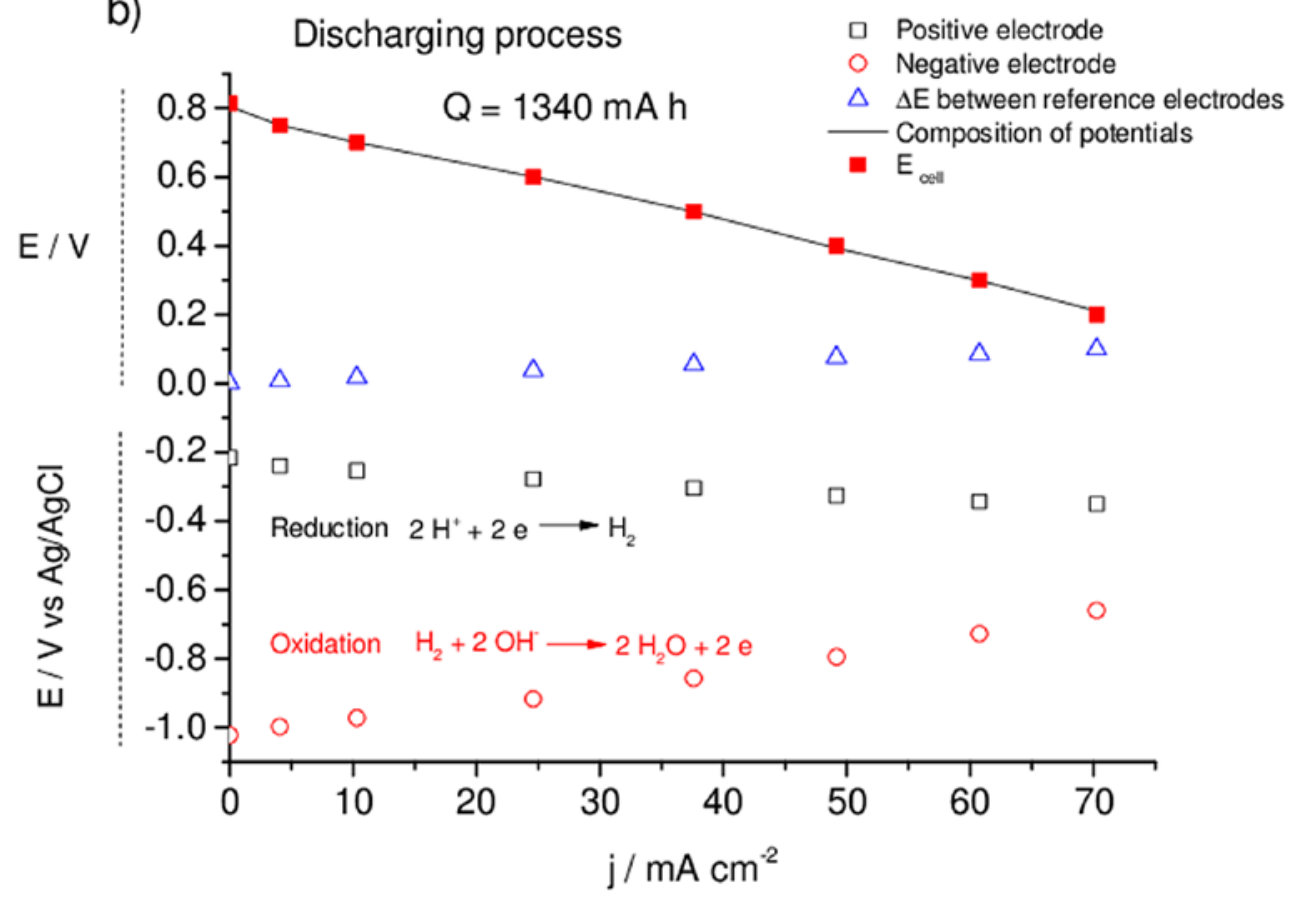

Figure 4 


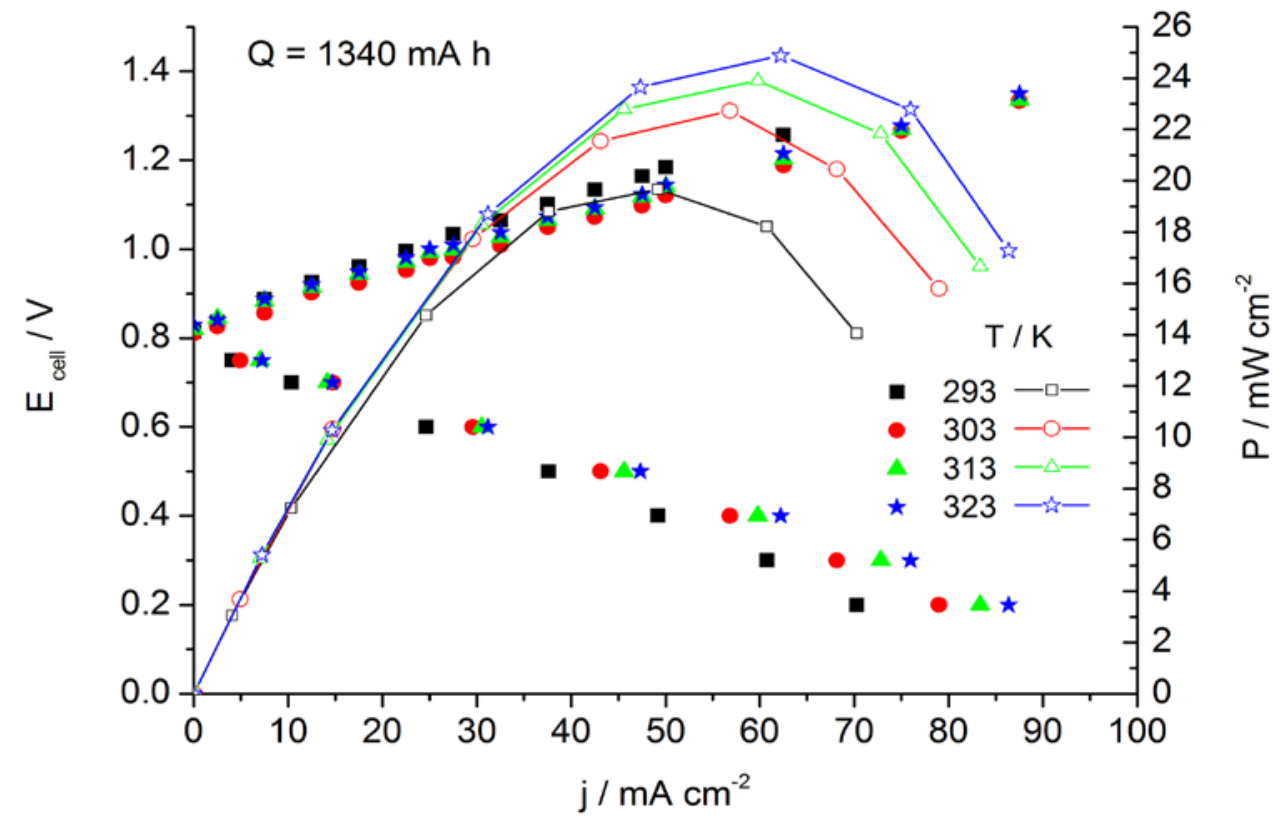

Figure 5 